\title{
THE LOCUS OF CONTROL AND THE SENSE OF PERSONAL COMPETENCE IN YOUNG ATHLETES PRACTICING MARTIAL ARTS
}

\author{
LOC and competences of young athletes
}

\author{
KATARZYNA RUTKOWSKA ${ }^{1}$, JAROSŁAW KLIMCZAK ${ }^{2}$ \\ ${ }^{1}$ The Jozef Pilsudski University of Physical Education in Warsaw, \\ Faculty of Physical Education and Sport in Biała Podlaska, Department of Psychology \\ ${ }^{2}$ University of Warmia and Mazury in Olsztyn
}

Mailing address: Katarzyna Rutkowska, Faculty of Physical Education and Sport, Department of Psychology, 2 Akademicka Street, 21-500 Biała Podlaska, tel.: +48 83 3428779, fax: +48 833428800 ,

e-mail: kr@psychologsportu.pl

\begin{abstract}
Introduction. The locus of control and the sense of competence are the psychological resources relevant to the taking-up and continuation of actions in certain situations. They are important regulating factors of the relationships between the man and the environment. It seems that, in such a specific field as martial arts are, these characteristics are useful and their identification and targeted strengthening desirable. The aim of the research presented in this paper was to gather knowledge about the sense of competence and self-control of young people practicing martial arts, as well as the relationship between these variables. Materials and methods. A total of 39 people aged 14-19 years participated in this research. All of them practiced martial arts. They had an average of more than two years training. Data were collected through the (KBPK) Locus of control Questionnaire (by G. and A. Krasowicz Kurzyp-Wojnarski) and the Personal Competence Scale KompOs (by Z. Juczyński), and a questionnaire designed specifically for this research. Results. Statistical analyses conducted for the study have showed that the respondents represent a transient sense of locus of control, and average levels of personal competence in the field of strength and perseverance. Out of the measured variables, the locus of control in the event of success and a sense of strength were relatively highest. These variables also proved to be interdependent. Analysis also allowed for identification of many other relationships between the variables. Conclusions. Our findings may provide a clue for a possible modification of programs mentally preparing young athletes for martial arts sports. They may also act as suggestions sensitise trainers to specific psychosocial needs of young athletes.
\end{abstract}

Key words: sense of competence, locus of control, young people, martial arts sports, sports psychology

\section{Introduction}

LOC - locus of control, understood as a relatively stable personality trait and/or cognitive mechanism, constitutes an individual characteristic co-regulating the effectiveness of human functioning. It is a relatively stable belief as to the results of actions. It is precisely this perception, definition, and, finally, the valuation of the situation, rather than the reality determine the behaviour. LOC is located on the continuum - from internal to external locus of control. Internal LOC is particularly important in the case of behaviour control, as it determines effective actions. It is related to the belief in the possibility of taking action and eventual success. Such confidence is decisive, when it comes to initialising of actions, and further the perseverance, effort and involvement related feelings [1, 2, 3, 4, 5, 6, 7, 8]. Internal LOC is sometimes equated with a sense self-efficacy, and this is sometimes associated with self-esteem and the sense of personal competence. The sense of competence is related to the strength and the commitment as well as perseverance in action $[9,10,11]$. The concepts of the locus of control and the sense of personal competence are not identical, although they are close (especially in generalised scenes). They relate to specific psychological resources of the man. In addition, within each of the- se construct, one can extract specific variables, which were included in this study.

The purpose of this study was precisely to diagnose these variables: 1 / locus of control (generalised and specific, relating to the successes and failures), and 2/ sense of personal competence (generalised and specific, relating to the strength and perseverance in action) in young people practicing martial arts. Due to the recommendation that "the measurement of generalised self-efficacy, in the case children, requires specific task situations, the solution of which depends on their competence" [11] relationship between these variables was also examined as part of our study. Our findings may provide guidance to persons involved in sports training, and its inherent element in modern sports -i.e. mental preparation of young athletes.

\section{Material and methods}

A total of 39 subjects participated in the study (2 girls and 37 boys) aged $14-19(\mathrm{M}=15,85, \mathrm{SD}=1,46)$. These included participants of summer camps - from Mazowieckie Voivodeship organised as part of a nationwide campaign in "Sport as a means of preventing violence amongst children and youths". 


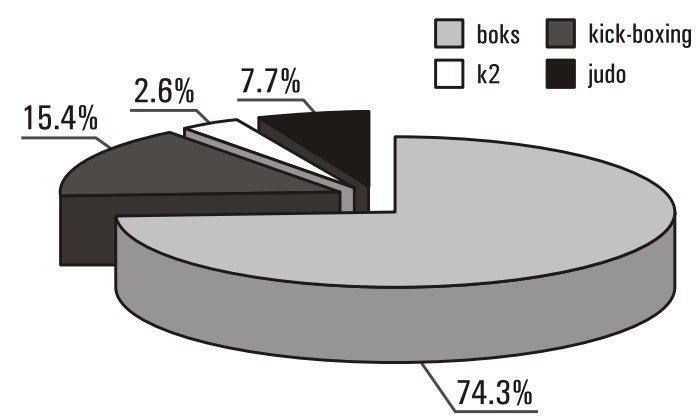

Figure 1. Disciplines practiced by the subjects

The subjects practiced various martial arts sports (Figure 1). Their training experience was between six months and 9 years $(\mathrm{M}=2,24, \mathrm{SD}=2,08)$. Their weekly training loads varied between 1 and 10 hours $(M=5,6, S D=2,48)$.

During the course of the study the following methods were used:

- KompOs Scale - Personal Competence Scale contains 12 statements measuring the sense of competence defined as generalised self-efficacy, the first 6 items beliefs deal with the belief of having the necessary strength to initiate actions, while remaining items are designed to diagnose the perseverance necessary to continue the course of action, the diagnosis also involved the general sense of competence (Ko subscale) measured by the overall result obtained during testing according to the aforementioned scale [11]

- KBPK Questionnaire - Locus of control Questionnaire consisting of 46 questions grouped within 2 sub-scales - $S$ (diagnosis of LOC in success situations) and P (analysis of LOC in failure situations); another significant result involved algebraic sum of both scales $\mathrm{S}$ and P, i.e. the total result $(\mathrm{Og})$ determining the generalised level of LOC; with analysis performed using this scale, it is assumed that the higher the result the more internalised is the diagnosed locus of control $[5,12,13]^{1}$;

- MS questionnaire (M - youths, S - sport; prepared for the purpose of this study) - containing background information and two 10 point scales used by the subjects to mark: $1 /$ the level of satisfaction drawn from the sport, 2/ self assessment of their sporting skills (the higher the value the higher the level of the variable).

The survey was of pen and paper nature. Each respondent individually completed the questionnaires. Descriptive statistics were used for the purpose of the analysis. However for comparisons between the groups and correlation analysis, due to the size of the sample, non parametric tests were used .

\section{Results}

When completing the questionnaire the subjects assessed their satisfaction from the sport $(M=9,18, S D=1,07)$. They also assessed their level of skill in the sport $(M=6,49, S D=1,94)$. Figure 2 presents the assessment categories; determined using the scale applied with respect the sten scores (1-4 low scores, 56 average scores, 7-10 high scores).

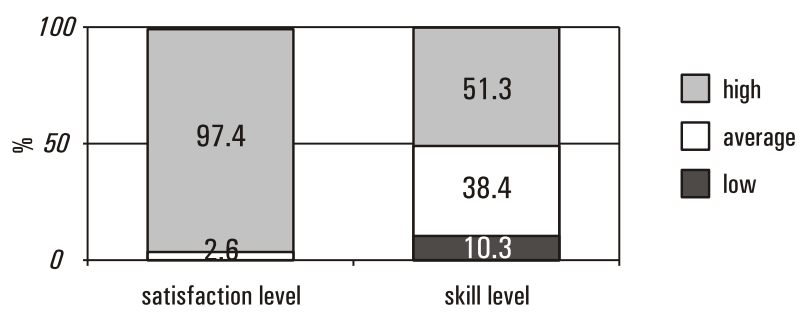

Figure 2. Summary of scores in the category of self assessment of satisfaction and assessment of sporting skills

Most of the subjects (over 97\%) reported high levels of satisfaction drawn from the sports. Over half of them highly assessed their sporting skills; while every tenth respondent believed otherwise. It is worthwhile adding that there is a relationship between the measured variables; the subjectively felt satisfaction is related to the actual sporting performance $(\mathrm{r}=0,38$, $\mathrm{p} \leq 0,05)$.

Table 1. Survey results - KompOs Scale and KBPK Questionnaire

\begin{tabular}{|c|c|c|c|c|c|c|c|}
\hline \multirow{2}{*}{ Scale } & \multirow{2}{*}{ Sub-scale } & \multicolumn{3}{|c|}{ Raw scores } & \multicolumn{3}{c|}{ Converted scores } \\
\cline { 3 - 8 } & & bracket & M & SD & bracket & M & SD \\
\hline \multirow{4}{*}{ KBPK } & S & $8 \cdot 18$ & 13.56 & 2.66 & $3 \cdot 10$ & 6.79 & 2.19 \\
\cline { 2 - 8 } & $\mathrm{P}$ & $5 \cdot 18$ & 12.90 & 3.48 & $1 \cdot 10$ & 5.33 & 2.45 \\
\cline { 2 - 8 } & Og & $14 \cdot 36$ & 26.46 & 5.22 & $1 \cdot 10$ & 6.08 & 2.43 \\
\hline \multirow{4}{*}{ Komp0s } & $\mathrm{A}$ & $12 \cdot 24$ & 19.15 & 2.53 & - & - & - \\
\cline { 2 - 8 } & $\mathrm{B}$ & $9 \cdot 24$ & 17.08 & 3.60 & - & - & - \\
\cline { 2 - 8 } & Ko & $24 \cdot 48$ & 36.23 & 5.27 & $1-10$ & 6.43 & 2.02 \\
\hline
\end{tabular}

The general sense of competence level of the respondents (measured based on the KompOs Scale) can be defined as higher than average. Although there are no standards for the results of the two sub-scales, however, it is possible to analyse the differences between the averages. Having applied the Wilcoxon test, it can be concluded that the respondents had more strength than perseverance $(Z=-3,36, p \leq 0,01)$.

The generalised level of control in the tested group could be defined as higher than average. It was similar in the case of the result obtained by the young people on the "s" subscale relating to the level of control in the event of success. The subjects also had average level of the sense control in the event of failure.

Using the Wilcoxon test it was also possible to determine differences between the averaged sten scores, the result of these analyses allowed gave the basis for development of the following formula: $\mathrm{S} \mathrm{Og}$ P. The respondents appeared to have sense of the level of control in the event of success than failure $(\mathrm{Z}=-3.17, \mathrm{p} \leq 0.01)$ and greater than the generalised LOC $(\mathrm{Z}=-2.67, \mathrm{p} \leq \mathrm{0.01})$. The global level of control was, however, hi-gher than that relating to the situation of failure $(Z=-3.31$, $\mathrm{p} \leq 0.01$ ).

Figure 3 presents categories of sten scores obtained by the subjects. The majority of them (almost 60\%) had internalised locus of control in the event of success. However, over $10 \%$ of

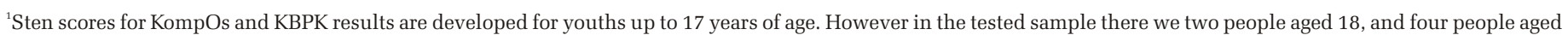
19. Therefore the references to sten scores appearing in this paper are treated rather as an approximate assessment of the tested variables. 
the subjects had external locus of control in this area. Less than half of respondents had internalised locus of control in failure situations. The others had external or undefined locus of control with respect to failures. Analysing the results within the $\mathrm{Og}$ subscale one can say that every fourth respondent had internal LOC, in turn, $1 / 4$ of the tested group had external locus of control. Nearly half of the respondents had high sense of competence.

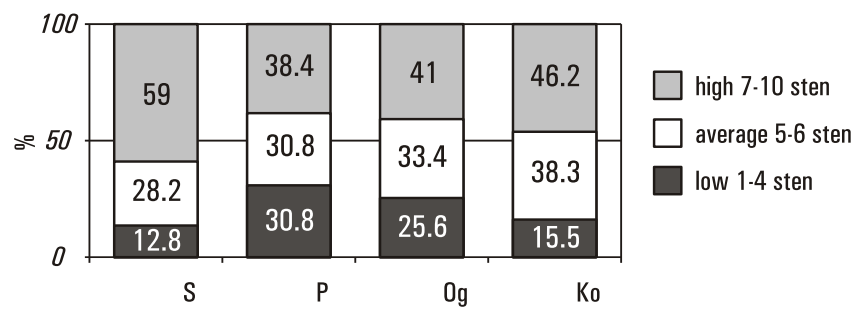

Figure 3. Specification of sten scores in subscales KompOs and KBPK

The subsequent analyses involved determination of relationship between the variables ${ }^{2}$. Table 2 presents significant correlation coefficients. There were moderate to high inter-correlations between the results of subscales KompOs Scale as well as KBPK. In addition, a positive correlation was detected between the sense of strength and the locus of control in the event of success. The sense of perseverance, as well as the generalised sense of competence is correlated to both, the generalised LOC and situational LOC (both, in the case of success and failures).

Table 2. Correlations between results within subscales KompOs and KBPK

\begin{tabular}{|c|c|c|c|c|c|c|c|}
\hline $\begin{array}{c}\text { r.Pearson } \\
\text { correlations }\end{array}$ & Scale & \multicolumn{3}{|c|}{ KBPK } & \multicolumn{3}{|c|}{ KompOs } \\
\hline Scale & Subscale & S & P & Og & A & B & Ko \\
\hline \multirow{3}{*}{ KBPK } & S & XXX & & & & & \\
\cline { 2 - 8 } & $\mathrm{P}$ & $0.89^{* *}$ & $\mathrm{XXX}$ & & & & \\
\cline { 2 - 8 } & $\mathrm{Og}$ & $.81^{* *}$ & $.88^{* *}$ & $\mathrm{XXX}$ & & & \\
\hline \multirow{3}{*}{ Komp0s } & $\mathrm{A}$ & $.36^{*}$ & .13 & .27 & $\mathrm{XXX}$ & & \\
\cline { 2 - 9 } & $\mathrm{B}$ & $.36^{*}$ & $.34^{*}$ & $.39^{* *}$ & $0.89^{* *}$ & $\mathrm{XXX}$ & \\
\cline { 2 - 9 } & $\mathrm{Ko}$ & $.43^{* *}$ & $.35^{*}$ & $.45^{* *}$ & $0.49^{* *}$ & $0.79^{* *}$ & $\mathrm{XXX}$ \\
\hline
\end{tabular}

${ }^{*} \mathrm{p} \leq 0.05,{ }^{*} \mathrm{p} \leq 0.01$

Interesting inter-dependencies were also noted between the level of satisfaction from the sport and the $S$ subscale $(\mathrm{r}=0.37$, $\mathrm{p} \leq 0.05)$ and the $\mathrm{Og}$ subscale $(\mathrm{r}=0.36, \mathrm{p} \leq 0.05)$. Self-assessment of the subjects' sporting performance was also related to the level of locus of control, however this was found in the case of the three subscales: $\mathrm{S}(\mathrm{r}=0.36, \mathrm{p} \leq 0.05), \mathrm{P}(\mathrm{r}=0.33, \mathrm{p} \leq 0.05)$ and $\mathrm{Og}(\mathrm{r}=0.40, \mathrm{p} \leq 0.01)$. A significant correlation was also observed between the level of skill and sport and the personal competence as far as initiation of action was concerned - strength $(\mathrm{r}=0.32, \mathrm{p} \leq 0.05)$. It is also worth noting that the result showing the level of competence and the sense of personal strength was related to the length of the training experience is measured in years (relevant values: $\mathrm{r}=0.32, \mathrm{p} \leq 0.05$ and $\mathrm{r}=0.35, \mathrm{p} \leq 0.05$ ). None of the variables tested was correlated to the age subjects.
Satisfaction from sports was correlated with the level of selfassessment of the subjects skills ( $\mathrm{r}=0.38, \mathrm{p} \leq 0.05)$, while the length of the training experience - was correlated with the weekly training load measured in hours $(r=0.56, p \leq 0.01)$.

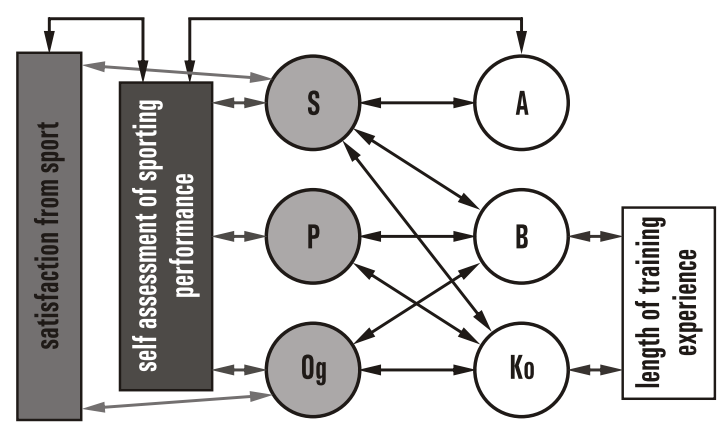

Figure 4. Graphical presentation of all the identified correlations

Figure 4 presents all the detected inter-relations between the variables tested in this study.

\section{Discussion}

In accordance with information found in the literature, the examined variables are associated with effectiveness not only in sport, but also in other areas of human activity $[6,14,15,16,17$, $18,19]$. It should be noted that modern education in sport and through sport should prepare young people not only for competitive sports, but also for other roles in life [20]. Nowadays we should promote the model of sportsman who is "an active, creative and transgressive person, striving not only for better sporting achievements, but also to perfect himself/herself as a person" [21]. The variables studied seem to be important in process. Their level diagnosed in the young people seems to be insufficient. The results of this research, in addition to the value of information can be a source of application of theory to practice. They can provide guidance as to a directional change in mental preparation programs conducted thus far, or otherwise implementation of corrective actions.

They can also be a pretext for taking action to improve the identification of these variables not only on the basis of everyday situations (which was allowed by the tools used in the study), but also in sports. In the literature it is suggested that the sense of efficacy, the sense of control should be considered from the point of view of multi-dimension, analysing its components also in reference to the specific activity in sports [6, 22]. It is necessary to use the achievements of other branches of psychology, confront the theory with the results of empirical research and constantly search for factors that increase the effectiveness [23], and this includes the variables investigated within this study. It is therefore necessary to create or adapt new methods of research in the psychology of sport. An interesting proposal is to use study methods applied in the psychology of health [11]. This direction is important, especially in the light of new threats, such as the holistic concept of athletes' health.

Analysis of the results of this study have shown no relationship between the level of control and the age of the respondents. This may be due to the fact that this relationship is non-linear, 
and young people in the group were at various stages of development - from early to late adolescence. This is exactly, when characteristic changes LOC appear: the predominance of internal LOC (in early adolescence) changes towards integration of internal and external LOC (in adolescence). However, not only the generalised LOC level changes. The changes also apply to LOC in specific situations of successes and failures. Initially, the external LOC, which is to do with success and failure, internalises primarily at the level of successful operations. Ultimately, LOC is shaped with predominance of external or internal locus [14, 24, 25].

What is puzzling, is the lack of relationship between the length sporting experience, the sporting level (subjectively perceived), and satisfaction drawn from sports. It is worthwhile to subject these variables to more in-depth analysis. This is important in the context of the well-known problem of young people giving up sports.

In the course of the study, it was found that the sense of control was relatively highest in the event of success, while the sense of competence was highest in the area of strength. In addition, these variables are interdependent. What seems puzzling, is the lack of the relationship between the strength and other measures the locus of control. Perhaps only a more strongly internalised LOC (and not transient) is a pretext for arousing a greater sense of strength.

According to the study more than $25 \%$ of the respondents have a sense of external locus of control, generalised as well as situational in circumstances relating to failures. This is a signal suggesting the need specifically oriented corrective actions group - to strengthen the sense of internal locus of control, situational as well as generalised. It is also worthwhile to consider strengthening the sense of competence - especially perseverance $^{3}$, and strength (especially in the case of failure situations). In this context, a significant impact can be exerted by a relatively higher level of control in the event of success. Such characteristics favour tendencies to undertake action in the area of education and training. According to the indications for the development of internal locus of control it is necessary to practice independence and self-sufficiency [5]. Sport is an excellent field for this type of training. Experiences gained in social sporting situations can become a source of self-education [26, 27], and creation of one's own expectations [1, 7]. Reflecting on, and assessment of experiences are basis for learning. Coaching, and especially the coaching dialogue is valuable in this process [28, 29]. It should be carried out by persons significant to the young man. A reasonable support, first from the parents, and then other educational environments is a significant factor for the development of a healthy LOC [5]. This is a good pretext for discussion about the model of effective cooperation and joint implementation of educational consistence presented by the various environments (family, club, school). Also the impact of the peer group is important, in this case, it is the sports group. Although the martial arts are individual sports, however, functioning within a group is an inherent part of physical activity. It is worthwhile to consider the proposal to organise meetings with other athletes (especially those with high levels of the desirable features) [30]. Contact with champions, enhanced by appropriate comments from a coach/parent can be a beneficial platform for modelling appropriate attitudes. A parent/guardian with a strong internal LOC constitutes an enhancement of the child's LOC [5]. It is worthwhile to build he right kind of team organisational culture, and to reinforce desirable forms of social behaviours. It seems that in this respect, it is a good idea to use not only the achievements of sports psychology, but also those of other branches - for example, management psychology, especially the sports and business (as well as other environmental, whose representatives are struggling with the stress, and are expected to maximise results) have many points of contact [31, 32].

A relatively small group took part in the study $(\mathrm{N}=39)$. The authors are aware that study is of a pilot nature, however, it allows for identification of certain trends, as well as considering them in a broader context. The participation of just two girls (and 37 boys) is a signal that the martial arts are still stereotypically perceived - as a traditionally male discipline. The choice of the sample was based on comparable sporting levels, as well as the age of subjects. As a result, the diagnosed levels of variables and the relationship between them, may be an indication for a discussion on the psychological elements of youth sports training.

\section{Conclusions}

Young people practicing martial arts present an average level of LOC relating to situations of failure. Higher average scores were obtained by the subjects in generalised LOC. The highest, of the analysed variables, was the level of control in the event of success. However, the level of these variables, ranks at the average level, which implies that the subjects' LOC is transient. The sense of competence was also at a similar level, however the sense of strength was significantly higher than the sense of perseverance. Due to the beneficial effects of the tested variables (especially if all of them are considered at the same time, and not as isolated variables) it is worthwhile to discuss possible modification and enrichment of sports specifically oriented educational activities.

\section{Literature}

1. Rotter, J.B. (1966). Generalized expectancy for internal versus external control of reinforcement. Psychological Monographs 609, 80, 1-28.

2. Drwal, R.Ł. (1978). Sense of control as a dimension of personality - theoretical basis, experimental techniques and study results. In L. Wołoszynowa (Ed.), Psychology Teaching Materials 3, 307-345.

3. Domachowski, W. (1984). Locus of control as a dimension of personality. In W. Domachowski, S. Kowalik \& J. Mikulska (Eds.), Social psychology issues (pp. 37-51). Warszawa: PWN.

4. Domańska-Najder, K. (1984). Definition of the sense control - a review of issues. Przeglad Psychologiczny 24/2, 405-421.

5. Krasowicz, G. \& Kurzyp-Wojnarska A. (1990). Questionnaire for testing the locus of control. Handbook. Warszawa: PTP, LTP, UW.

6. Gliszczyńska, X. (1990). I-E scale at work. A technique for measurement the sense of control at work. Warszawa: Pracownia Testów Psychologicznych.

7. Szmigielska, B. (1999). Julian B. Rotter's social and learning theory of personality. In A. Gałdowa (Ed.), Classic and contemporary concepts of personality 1 (pp. 209-223). Kraków: UJ.

8. Oleś, P.K. \& Drat-Ruszczak K. (2008). The Personality. In J. Strelau \& D. Doliński (Eds.), Psychology. An academic Handbook 1 (pp. 651-761). Gdańsk: GWP.

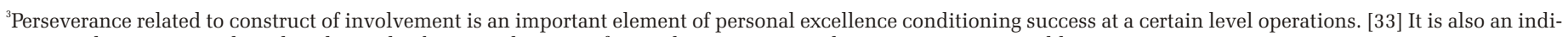
cation to do more research on the relationship between the sense of control, competence and commitment among athletes. 
9. Bandura, A. (1997). Self-efficacy: The exercise of control. New York, USA: Freeman.

10. Schwarzem, R. (1997). The Sense of self-efficacy in the undertaking and continuation of health oriented behaviours. The existing theoretical approaches and a new model. In I. Heszen-Niejodek \& H. Sęk (Eds.), Health Psychology (pp. 175-206). Warszawa: PWN.

11. Juczyński, Z. (2001). Measurement tools in the promotion and psychology of health. Warszawa: Pracownia Testów Psychologicznych.

12. Kurzyp, A. \& Krasowicz G. (1987). Questionnaire for measurement of the sense of control in adolescents. In R.Ł. Drwal (Ed.), Questionnaire techniques in psychological diagnosis. Selected issue (pp. 39-61). Lublin: UMCS.

13. Krasowicz, G., Kurzyp A. \& Drwal R.Ł. (1985). The KBPK questionnaire as a reliable and accurate method for measuring the sense of control in adolescents. Psychologia $W_{y-}$ chowawcza 1, 28, 81-92.

14. Kulas, H. (1998). Developing a sense of control in school age children. Psychologia Wychowawcza 3, 219-230.

15. Bielec, G. \& Lipowski M. (1998). The impact of the sense of control on the results of high-class swimmers. Trening 2-3, 267-271.

16. Lipowski, M. (1998). Neuroticism and locus of control as determinants of gymnasts behaviour. In T. Rychta (Ed.). Personality and goal-directed behaviour in sport (pp. 157-167). Warszawa: COS.

17. Sankowski, T. (2001). Locus of control and the activity of athletes. Kultura Fizyczna 3-4, 7-9.

18. Mikicin, M. (2007). Relationships between experiencing flow state and personality traits, locus of control and achievement motivation in swimmers. Physical Education and Sport 51, 61-67.

19. Gencer, E. (2010). The relationship between locus of control, self-esteem and goal orientation, motivational climate in badminton players. Ovidius University Annals, Series Physical Education and Sport, Science, Movement And Health 10, 2, 157-162.

20. Petitpas, A. Champagne D., Chartrand J., Danish S. \& Murphy S. (1997). Athlete's Guide to Career Planning. Keys to Success From the Playing Field to Professional Life. Champaign: Human Kinetics.
21. Rychta, T. (2008). The Polish sports psychology. The past the presents - the future. In M. Plopa \& M. Błażek (Eds.), The modern man in the light of the dilemmas and challenges: a psychological perspective (pp. 285-306). Kraków: Impuls.

22. Nicholas, A.R., Polman R. \& Levy A.R. (2010). Coping selfefficacy, pre-competitive anxiety, and subjective performance among athletes. European Journal of Sport Science 10, 97-102.

23. Gardner, F.L. (2009). Efficacy, mechanisms of change, and the scientific development of sport psychology. Journal of Clinical Sports Psychology 3, 139-155

24. Lawrence, E. \& Winschel J. (1975). Locus of control implications for special educations. Exceptional Children 41, 483490.

25. Oppenheimer, L., Stet A. \& Versteeg E. (1986). Relations among conceptions of control and autonomy and other personality variables: A developmental approach. European Journal of Psychology and Education 1, 93-102.

26. Kalina, R.M. (1997). Development - a realistic prospect of coaching an athlete. Trening 4, 36, 101-109.

27. Starosta, W. (2001). The importance and components of the self-education process in the sport of children and young people. Medycyna Sportowa 18, 2, 57-68.

28. Thrope, S. \& Clifford J. (2007). A coaching handbook. Poznań: Rebis.

29. Clutterbuck, D. (2009). Team coaching. Poznań: Rebis.

30. Feltz, D.L., Short S.E. \& Sullivan P.J. (2008). Self-efficacy in sport: Research and strategies for working with athletes, teams, and coaches. Champaign: Human Kinetics.

31. Hays, K.F. (2000). Breaking out: doing sport psychology with performing artists. In M. B. Andersen (Ed.), Doing Sport Psychology (pp. 261-274). Champaign: Human Kinetics.

32. Jones, G. (2002). Performance excellence: A personal perspective on the link between sport and business. Journal of Applied Sport Psychology 14, 268-281.

33. Orlic, T. (1997). In the circle of excellence. Sport Wyczynowy 1-2, 55-64.

Submitted: November 27, 2012

Accepted:December 24, 2012 